\title{
THE EFFECT OF DIFFERENT ORGANIC SOLVENTS OF FILLING REMOVAL DURING ENDODONTIC RETREATMENT
}

\author{
Nourhan Esmat", Abeer El Gendy** and Ahmed Khalaf***
}

\begin{abstract}
Objectives The aim of the study was evaluation of the effectiveness of three different solvents (orange oil solvent, eucalyptol oil solvent, and chloroform) during retreatment regarding: root canal filling removal

Methods were 33 premolar root canals were prepared by using Protaper universal files for cleaning and shaping, obturation was done by lateral compaction technique. Samples were divided $(n=11)$ Group A Chloroform, Group B orange oil, and Group C Eucalyptus oil according to the solvent used into three groups. Retreatment was done by combining two methods for filling removal as chemical by using organic solvents and mechanical by utilizing rotary retreatment files (Protaper retreatment files). Roots were split longitudinally, canals were observed using a stereomicroscope at $6 x$. The images were subjected to morphometric analysis to assess the amount of remaining root filling materials. Data were explored for normality using Kolmogorov-Smirnov and ShapiroWilk tests, data showed parametric (normal) distribution. Repeated measure ANOVA was used to compare between more than two groups in related samples.

Results: The highest mean value was found in (Group A) followed by (Group B), while the least mean value was found in (Group C). A statistically significant difference was found between (Group C) and each of (Group A) and (Group B) $(\mathrm{p}<0.001)$. No statistically significant difference was found between (Group A) and (Group B) $(p=0.853)$.
\end{abstract}

Conclusion: Chloroform and orange oil are preferable to be used in retreatment.

\section{INTRODUCTION}

Endodontic treatment occasionally fails due to persistent microbial invasion and extra-radicular infection. Furthermore, the occurrence of different endodontic mishaps during access cavity, root canal instrumentation and obturation act as supplementary factors that help in development of secondary apical periodontitis. The aim of endodontic treatment is to fully clean and disinfects the root canal system. Chemical dissolving of root canal filling materials

\footnotetext{
* Endodontics, Dentistry, Misr International University

** Professor, Endodontics, Dentistry, Ain shams University

*** Instructor, Endodontics, Dentistry. Misr International University
} 
is done by using different solvents. Chloroform is one of the most widely used solvents because of its efficiency, however it is known to be toxic. Oily solvents, which are alternatives to chloroform to avoid its toxicity, have been developed. These oilbased solvents such as orange oil and eucalyptol. Scarce data are available about the effectiveness of orange oil in removing root canal filling material.

\section{MATERIALS AND METHODS}

33 mandibular premolar roots were selected with the aid of illumination and magnification possessed the following; single rooted, no calcification or fractures, and no root caries.

The roots were horizontally cut to have a standard root length of $16 \mathrm{~mm}$. apical patency was obtained by size $15 \mathrm{~K}$-file. For all root samples, the root canals were prepared using ProTaper Universal system in a crown-down technique. SX (size 19, taper 0.035) was used to enlarge coronally giving enough space to act as an irrigant reservoir. S1 (size 17, taper 0.02) to enlarge the coronal third of the canal. S2 (size 20 , taper 0.04) to shape the middle third of the root canal. After shaping, F1 (size 20, 0.07) was used to finish the apical third followed by F2 (size 25, taper 0.08), F3 (size 30, taper 0.09). Irrigation was done using $3 \mathrm{ml} 2.5 \% \mathrm{NaOCl}$ irrigation in between each file size and the following. After instrumentation, the canals were dried using size 35 paper points.

Obturation was done conventionally; master cone was selected to be ISO size 35 taper 0.04 ,with $\mathrm{AH}$ Plus sealer mixing according to the manufacturer. Obturation was done by lateral compaction technique, Auxiliary cones were coated with the sealer and they were inserted till complete root canal filling was achieved. Excess Gutta-percha was removed using a hot condenser.

Radiographic assessment was done buccolingually and mesiodistally to ensure the quality of the obturation and apical closure of the obturation materials.
Retreatment was done for all samples, Root canal filling was removed using Protaper retreatment files in addition to the solvent used for each group: Group A: chloroform, Group B: orange oil, and Group C: eucalyptus oil. $1 \mathrm{ml}$ of solvent was used prior to each file of the Protaper retreatment system (D1, D2, and D3).

\section{Evaluation}

The roots were grooved labio-lingually using diamond discs to split roots into two halves, longitudinal sections were obtained by using a chisel Fig 1). The effectiveness of solvents was evaluated using stereomicroscope to calculate the mean $\%$ of the remaining filling material. Each root length was automatically measured and divided into cervical, middle and apical thirds.

Imaging of each half was undertaken by a digital camera mounted on Zoom Stereo Microscope at a magnification 6x. Images were then transferred to a computer system for image analysis.

\section{Image analysis}

The percentage of the remaining filling in each third of the root canal in relation to the total surface area of the root canal in this third was calculated using image analysis software (image $\mathbf{J}$ version $1.37 \mathrm{v}$, USA). Image was first automatically

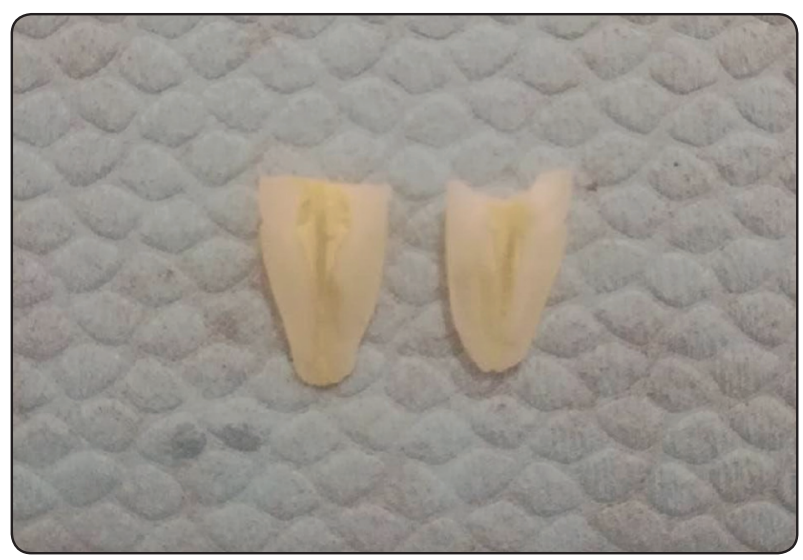

Fig. (1): longitudinal sections of root canal. 
corrected for brightness and contrast. The root canal area was selected and cut from the image. Then it was transferred to 8-bit monochrome image. The root canal image was then divided into three equal thirds. In each third, the color code thresholding

\begin{tabular}{|l|}
\hline $\begin{array}{l}\text { Step (1): Image after } \\
\text { automatic correction of } \\
\text { brightness and contrast }\end{array}$ \\
\hline $\begin{array}{l}\text { Step (2): Cutting of the root } \\
\text { canal from the surrounding } \\
\text { tissue }\end{array}$ \\
\hline $\begin{array}{l}\text { Step (3): Image transferal to } \\
\text { 8-bit monochrome }\end{array}$ \\
\hline
\end{tabular}

was performed twice to select the remaining filling material inside the canal then to select the total area of the canal. A binary image was generated for the desired area and the surface area was calculated automatically. Fig (2).

\begin{tabular}{|l|}
\hline $\begin{array}{l}\text { Step (4): Middle third of the } \\
\text { canal after division of the } \\
\text { canal into three equal thirds }\end{array}$ \\
\hline $\begin{array}{l}\text { Step (5): Color code } \\
\text { thresholding to select the } \\
\text { remaining filling material }\end{array}$ \\
\hline $\begin{array}{l}\text { Step (6): Generation of binary } \\
\text { image to calcula te the desired } \\
\text { surface area }\end{array}$ \\
\hline
\end{tabular}

Fig. (2) Plate representing steps of image analysis to calculate the area percentage of the remaining filling using image $\mathbf{J}$ software.

\section{RESULTS}

Coronal: The highest mean percentage of the remaining filling material value was found in (Group A, chloroform) followed by (Group C, eucalyptus oil), while the least mean value was found in (Group B, orange oil) group. There was a statistically significant difference comparing Group A with each of group B, and C where $(p<0.001)$. Middle: The highest mean percentage of the remaining filling material value was found in Group
A followed by Group B, while the least mean value was found in Group C. No statistically significant difference was found between the three groups.

Apical: The highest mean percentage of the remaining filling material value was found in (Group A) followed by (Group B), while the least mean value was found in (Group C) . There was a statistically significant difference between Group A, B and $\mathrm{C}$ where $(p<0.001)$.

TABLE (1) The mean, standard deviation (SD) values of percentage of remaining filling material of different groups:

\begin{tabular}{|l|c|c|c|c|}
\hline \multirow{3}{*}{ Variables } & \multicolumn{4}{|c|}{ Remaining debris \% } \\
\cline { 2 - 5 } & Group A (chloroform) & Group B (orange oil) & Group C (eucalyptus oil) & \multirow{2}{*}{ P-value } \\
\cline { 2 - 5 } & Mean \pm SD & mean \pm SD & Mean $\pm S D$ & $<0.001^{*}$ \\
\hline \multirow{2}{*}{ Coronal } & $47.00 \pm 8.45^{\mathrm{a}}$ & $24.29 \pm 3.04^{\mathrm{b}}$ & $30.71 \pm 6.07^{\mathrm{b}}$ & $0.011 \mathrm{~ns}$ \\
\hline Middle & $30.14 \pm 6.72$ & $26.29 \pm 4.99$ & $17.00 \pm 9.76$ & $<0.001^{*}$ \\
\hline Apical & $53.14 \pm 9.42^{\mathrm{a}}$ & $40.00 \pm 9.40^{\mathrm{b}}$ & $22.29 \pm 5.35^{\mathrm{c}}$ & \\
\hline
\end{tabular}

*; significant $(p<0.05) \quad n s ;$ non-significant $(p>0.05)$ 


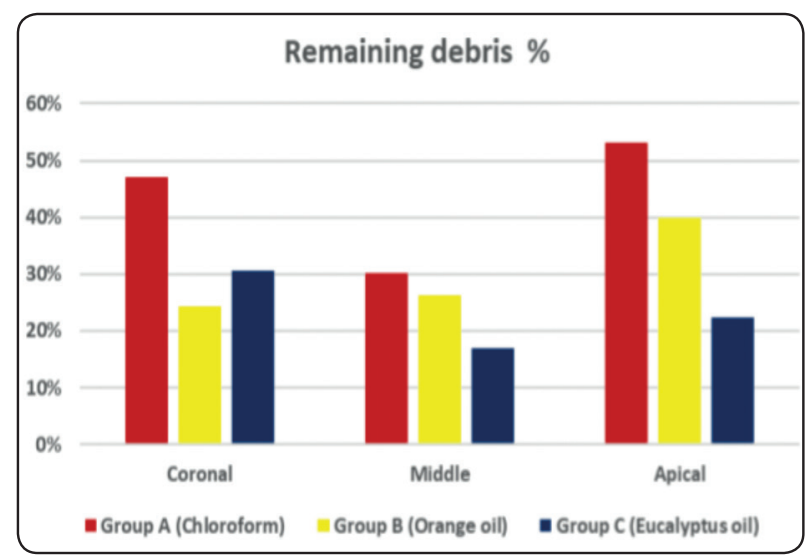

Fig. (3): Bar chart representing percentage of remaining debris for different groups.

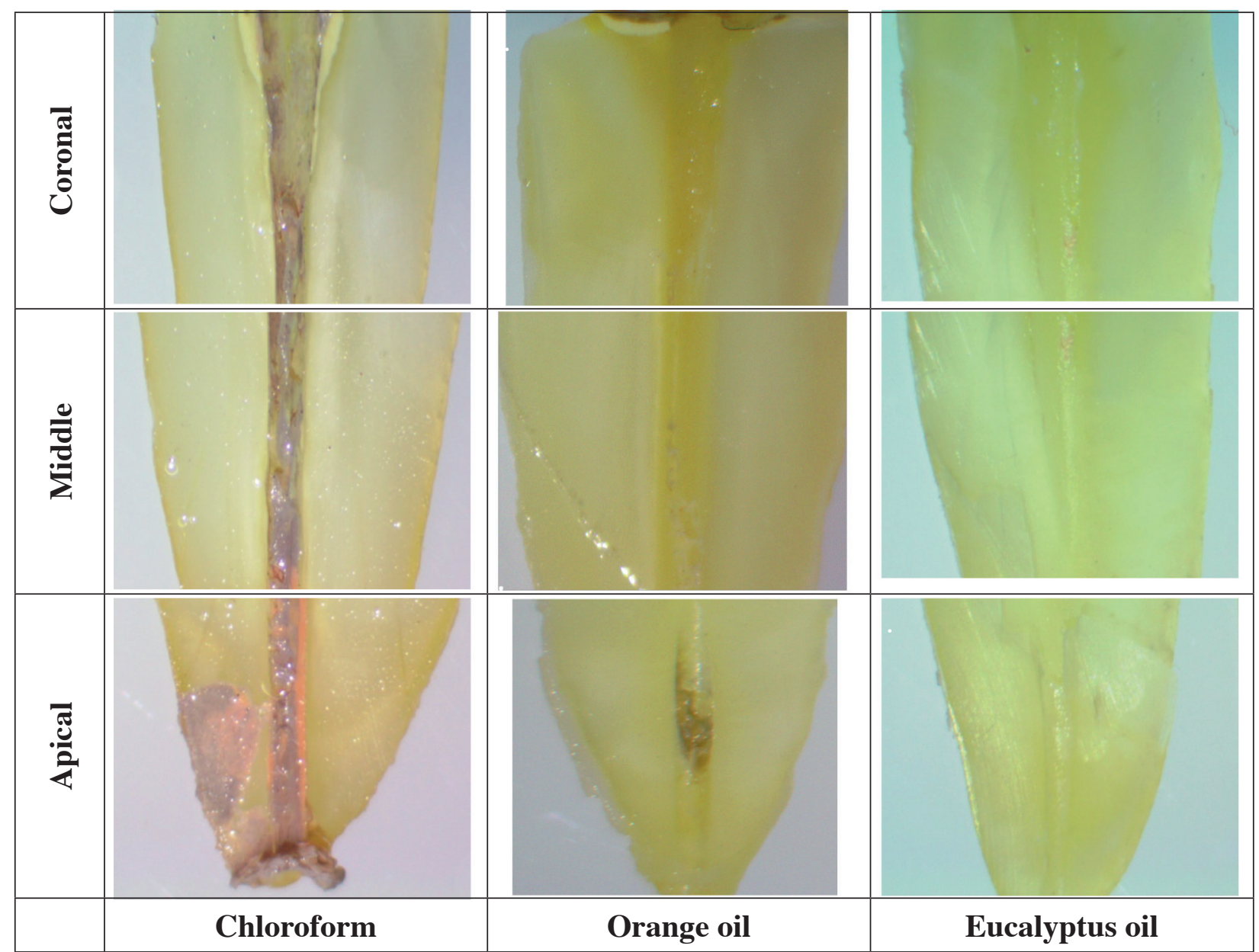

Figure (4): stereomicroscopic photos showing differences in solvent action among different thirds. 


\section{DISCUSSION}

Failure of endodontic treatment can be caused by multiple reasons; the main cause is re-introduction of microorganisms inside the root canal system causing reinfection and secondary apical periodontitis. The quality of the root canal filling regarding sealing of the root canal at full working length is the main determining factor which promote secondary apical periodontitis

Endodontic retreatment can be a challenging step as the removal of gutta percha must be done properly to ensure full removal of previouslly failed filling and existing bacteria, to enhance the chances of healing and success of the retreatment procedure. Removal of existing filling can be done by various ways solely or by a combination of two or more methods, mechanical, chemical, or thermal methods are the common methods.

The use of solvents is proved to facilitate the removal of gutta percha as it softens the root canal filling and solvents are effective with different sealers. ${ }^{1}$ Chloroform has proven to have great results in the removal of root canal filling materials, ceramic sealers, epoxy resin sealers, and even resilon. ${ }^{2,3}$ Its efficacy and ability to dissolve root canal filling material has been proved but its cytotoxicity had been questioned if it passed to the periapical tissues. ${ }^{4}$ Chloroform was questioned by the food and drug administration but was proven that it has no negative effects on the patient nor the dentist. ${ }^{5}$

Eucalyptol has an advantage that it is biocompatible, non-toxic and a safer option. ${ }^{6}$ Eucalyptus oil is an alternative to chloroform, it has an added benefit that if heated its dissolving ability increases and the dissolving process accelerated. ${ }^{7}$

Orange oil had a lot of attention and it was considered a good alternative to chloroform with close results of efficacy and dissolving of root canal filling material. Orange oil in comparison to chloroform and eucalyptus oil was the least cytotoxic among the three solvents. ${ }^{8}$
Evaluation of the dissolving ability of these solvents was measured by analyzing remaining filling material on the dentinal walls. It is trusted that there is no method ensures full removal of endodontic filling material. The use of solvents with rotary system causes more soften gutta percha which make the dentinal tubules more prone to be blocked by the softened filling. ${ }^{9}$ This evaluation could not be done by CBCT to avoid the common artifact of beam hardening. ${ }^{10}$ Radiographs lack the 3 dimensional feature so it would miss valuable information. The stereomicroscope was the method of choice as it allows a precise magnification and vision to the root canal system. Also can analyze the root in 3 dimensional visions and visualize the root as a whole. ${ }^{11}$

Regarding to the efficiency of different solvents in root canal filling removal, there was a significant difference between eucalyptus, orange oil on one side and chloroform on the other side. This could be attributed to the similar dissolution capacity of Orange oil and eucalyptus as both have a softening action on the gutta-percha rather than dissolving action of chloroform hence gutta-percha became easier to be removed using the rotary files. ${ }^{3}$ Also it was proven that, eucalyptus oil had higher capacity once heated which occurred along with the friction of the rotary instruments. ${ }^{11,12}$ On the other hand, chloroform dissolves rather than softens the obturating materials, leaving residues on the canal walls and its fast evaporation makes the use of more and more solvent, which makes its use messy and inconvenient. ${ }^{3}$

Similar results were recorded using chloroform with PTUR as the results showed that chloroform presented the highest value for remaining root canal filling when used as a solvent. ${ }^{13}$ However, the results of the present study came in contradiction with other studies in which there was no difference in the capacity between these three solvents. ${ }^{1,9,14}$ This could be attributed to the different evaluation methods as they used immersion weight loss evaluation, while in this study a more clinical method using solvents and rotary files till reaching the working length. 
Regarding to the efficiency of the solvents in different thirds, eucalyptus dissolved better in both middle and apical thirds. This might be related to the effect of rotary retreatment files by inducing heat through the friction improving the softening effect of the eucalyptus. Also the different solvents dissolved in the middle third more than the coronal; As when inserting the solvent in this third (coronal) act as a reservoir and hence it keeps it in the canal for a longer time. The middle third is easily accessed more than apical with a wider cross section.

Evaluation of the dissolving ability of these solvents was measured by analyzing remaining filling material on the dentinal walls. It is trusted that there is no method ensures full removal of endodontic filling material. The use of solvents with rotary system causes more soften gutta percha which make the dentinal tubules more prone to be blocked by the softened filling. ${ }^{9}$ This evaluation could not be done by CBCT to avoid the common artifact of beam hardening. ${ }^{10}$ Radiographs lack the 3 dimensional feature so it would miss valuable information. The stereomicroscope was the method of choice as it allows a precise magnification and vision to the root canal system. Also can analyze the root in 3 dimensional visions and visualize the root as a whole. ${ }^{11}$

\section{CONCLUSION}

Chloroform and orange oil are preferable to be used in retreatment.

\section{REFERENCES}

1. Martos J, Gastal MT, Sommer L, Lund RG, Del Pino FA, Osinaga PW. Dissolving efficacy of organic solvents on root canal sealers. Clin Oral Investig. 2006 Mar;10(1):50-4.

2. Mushtaq M, Masoodi A, Farooq R, Yaqoob Khan F. The dissolving ability of different organic solvents on three different root canal sealers: in vitro study. Iran Endod J. 2012;7(4):198-202.
3. Gomes F. A., Daniel AP, Nunes RA. Nunes Fernandes, A. L.; Maniglia-Ferreira, C.; Meneses de Matos, H. R.; Nepomuceno, T. C. Efficacy of gutta-percha solvents used in endodontic retreatments. South Braz Oral Res; 2013.

4. Wilcox LR. Endodontic retreatment with halothane versus chloroform solvent. J Endod. 1995 Jun;21(6):305-7.

5. Gu LS, Ling JQ, Wei X, Huang XY. Efficacy of ProTaper Universal rotary retreatment system for gutta-percha removal from root canals. Int Endod J. 2008 Apr;41(4):288-95.

6. Patel E, Owen CP. The use of textural analysis to test the hardness and penetrability of three types of gutta percha cones when exposed to two endodontic solvents: research. S Afr Dent J. 2016;71:346-50.

7. Lee JK, Kwak SW, Ha JH, Lee W, Kim HC. Physicochemical Properties of Epoxy Resin-Based and Bioceramic-Based Root Canal Sealers. Bioinorg Chem Appl. 2017;2017:2582849.

8. Scelza MF, Oliveira LR, Carvalho FB, Faria SC. In vitro evaluation of macrophage viability after incubation in orange oil, eucalyptol, and chloroform. Oral Surgery. Oral Surg Oral Med Oral Pathol Oral Radiol Endod. 2006;•••:102.

9. Horvath SD, Altenburger MJ, Naumann M, Wolkewitz M, Schirrmeister JF. Cleanliness of dentinal tubules following gutta-percha removal with and without solvents: a scanning electron microscopic study. Int Endod J. 2009 Nov;42(11):1032-8.

10. Ketcham RA, Carlson WD. Acquisition, optimization and interpretation of X-ray computed tomographic imagery: applications to the geosciences. Comput Geosci. 2001; 27(4):381-400.

11. de Carvalho Maciel AC, Zaccaro Scelza MF. Efficacy of automated versus hand instrumentation during root canal retreatment: an ex vivo study. Int Endod J. 2006 Oct; 39(10):779-84.

12. Topçuoğlu HS, Demirbuga S, Pala K, Cayabatmaz M, Topçuoğlu G. The bond strength of adhesive resins to AH plus contaminated dentin cleaned by various gutta-percha solvents. Scanning. 2015 Mar-Apr;37(2):138-44.

13. Sherif D, Farag A, Darrag A, Shaheen N. Evaluation of root canals filled with bioceramic sealer after retreatment with two different techniques. Tanta Dent. J 2017, 14, 76.

14. Tanomaru-Filho M, Orlando T, Bortoluzzi EA, Silva GF, Tanomaru JM. Solvent capacity of different substances on gutta-percha and Resilon. Braz Dent J. 2010 Jan;21(1):46-9. 